Published in final edited form as:

J Microbiol. 2016 May ; 54(5): 339-346. doi:10.1007/s12275-016-6080-1.

\title{
Transcriptional control of sexual development in Cryptococcus neoformans
}

\author{
Matthew E. Mead ${ }^{1, O}$ and Christina M. Hull ${ }^{1,2, *}$ \\ ${ }^{1}$ Department of Biomolecular Chemistry, School of Medicine and Public Health, University of \\ Wisconsin-Madison Madison, WI 53706 \\ 2Department of Medical Microbiology \& Immunology, School of Medicine and Public Health, \\ University of Wisconsin-Madison Madison, WI 53706
}

\begin{abstract}
Developmental processes are essential for the normal life cycles of many pathogenic fungi, and they can facilitate survival in challenging environments, including the human host. Sexual development of the human fungal pathogen Cryptococcus neoformans not only produces infectious particles (spores) but has also enabled the evolution of new disease-related traits such as drug resistance. Transcription factor networks are essential to the development and pathogenesis of C. neoformans, and a variety of sequence-specific DNA-binding proteins control both key developmental transitions and virulence by regulating the expression of their target genes. In this review we discuss the roles of known transcription factors that harbor important connections to both development and virulence. Recent studies of these transcription factors have identified a common theme in which metabolic, stress, and other responses that are required for sexual development appear to have been co-opted for survival in the human host, thus facilitating pathogenesis. Future work elucidating the connection between development and pathogenesis will provide vital insights into the evolution of complex traits in eukaryotes as well as mechanisms that may be used to combat fungal pathogens.
\end{abstract}

\section{Keywords}

Transcription factor network; fungal sexual development; fungal pathogenesis; evolution

\section{Fungal survival and pathogenesis depend on diverse developmental responses}

Developmental events are central to the biology of both higher eukaryotes and microorganisms, including pathogenic fungi. In these processes new cell types are forged from precursors, resulting in astonishing complexity and the appearance of novel structures (Estella et al., 2012; Pittet et al., 2014). Frequently, developmental cells and structures

\footnotetext{
${ }^{*}$ To whom correspondence should be addressed: Dr. Christina M. Hull, 1135 Biochemistry Building, 420 Henry Mall, University of Wisconsin-Madison, Madison, WI 53706, Telephone: (608) 265-5441, Fax: (608) 262-5253, cmhull@wisc.edu.

Current address: Dr. Matthew E. Mead, Department of Biological Sciences, Vanderbilt University, Nashville, TN 37235
} 
exhibit unique traits that facilitate the ability of an organism to survive new environments. For pathogenic fungi, that new and harsh environment can be the human host, an ecological niche that includes a variety of immunological mechanisms that have evolved to inhibit microbiological growth. Researchers have leveraged relatively simple fungal systems for decades to understand not only the evolution and appearance of broad, complex processes like sexual development but also the emergence of pathogenesis.

Developmental processes in the three most common fungal pathogens (Candida albicans, Aspergillus fumigatus, and Cryptococcus neoformans) are intimately associated with disease. In $C$. albicans, the fourth most common cause of blood stream infections in United States hospitals, cell-type switching between white and opaque cells connects development to pathogenesis (Edmond et al., 1999). Opaque cells are able to mate and undergo development, and they can cause cutaneous disease (Kvaal et al., 1999; Miller and Johnson, 2002). White cells, in contrast, mate at an exceptionally low rate and can cause potentially life-threatening systemic disease, especially in immunocompromised individuals. Recent studies investigating possible mechanisms for these differences in disease presentation show that white and opaque cells interact with immune phagocytes in unique ways. Depending on the kind of phagocyte and the local environment, $C$. albicans cells are either phagocytosed and killed (white) or they are ignored (opaque) (Sasse et al., 2013). This suggests that the evolution of the requirement for phenotypic switching facilitated the appearance of a novel trait: survival in the antimicrobial environment of a human host.

Aspergillus fumigatus is another common human fungal pathogen that causes both invasive disease in immunocompromised patients and allergic disease in immunocompetent individuals (Denning, 2001; S.J. Lin et al., 2001). Sexual development has only relatively recently been described in $A$. fumigatus, although the presence of recombinant populations and mating type genes was known previously (Paoletti et al., 2005; O'Gorman et al., 2009). While the connection between virulence and development in $A$. fumigatus is still under active investigation, ascospores (the end products of sexual development in $A$. fumigatus) are known to be highly heat resistant relative to conidia (the end products of asexual development), and may aid in the survival and dispersion of the organism. In addition, it has been hypothesized that drug resistance in an A. fumigatus population in Europe arose from a relatively small number of individuals that then spread the trait to drug susceptible mating partners via sexual recombination (Camps et al., 2012).

One system that lends itself well to the study of both development and pathogenesis is that of the basidiomycete fungus Cryptococcus neoformans. The study of sexual development in C. neoformans is facilitated by the fact that it is a genetically tractable system with welldeveloped molecular tools. $C$. neoformans is also a cause of meningoencephalitis, primarily in immunocompromised individuals. Cryptococcosis is responsible for the deaths of approximately 600,000 people annually worldwide, mostly among those with AIDS in SubSaharan Africa (B. Park et al., 2009).

C. neoformans in the environment is found in association with tree bark, soil, and bird droppings. It is a haploid, budding yeast that is able to undergo a multicellular sexual development process that results in the production of spores, and population studies of 
isolated strains show that recombination can occur in the environment, including in SubSaharan Africa (Litvintseva et al., 2003). Spores are likely one of the infectious particles inhaled by humans; they are small (1-3 $\mu \mathrm{m}$ in size), able to survive harsh stresses (such as high temperature, desiccation, and reactive oxygen species), and cause disease in a mouse model of cryptococcal infection (Botts et al., 2009; Giles et al., 2009). As well as producing infectious particles, sexual development in $C$. neoformans has been shown to facilitate the evolution of drug resistance (Ni et al., 2013). Therefore, studies of the sexual cycle of $C$. neoformans are valuable not only for the insights they provide into fungal development and evolution but also for their contributions to our knowledge of a process that is intimately connected to the virulence of a human pathogen.

One strategy used by pathogenic fungi like $C$. neoformans to control both sexual development and virulence is the implementation of genetic networks constructed from diverse sets of transcription factors. Developmental networks are frequently controlled by a relatively large number of transcription factors that act as regulatory hubs and coordinate the expression of target genes (Kim et al., 2008; MacArthur et al., 2009; Nobile et al., 2012). Regulatory hubs are frequently members of protein families that have shared DNA-binding motifs that include the Zinc Finger, Hox/Homeotic, and High-Mobility Group (HMG) domains, and they are the building blocks on which selection occurs to yield the resulting network. In this review we will focus on the transcription factor networks that control sexual development in $C$. neoformans and their connections to virulence as a way to better understand the mechanisms that contribute to fungal disease.

\section{Cryptococcus neoformans undergoes robust sexual development}

Sexual development in $C$. neoformans has been shown to occur via two mechanisms: samesex ( $a$ only) and opposite-sex $(\mathbf{a} \times \mathbf{a})$ development. While both have been shown to occur under laboratory conditions, opposite-sex development is generally more robust (Lin et al., 2005). Two stable mating types ( $\mathbf{a}$ and $\mathbf{a}$ ) are present in $C$. neoformans and are specified by an approximately $120 \mathrm{~kb} M A T$ locus that contains $\sim 23$ genes. These genes are involved in pheromone production and sensing, the establishment of sex-specific cell identities, and other developmental pathways (Kwon-Chung and Bennett, 1978; Lengeler et al., 2000; Lengeler et al., 2002; Fraser et al., 2004). Sexual development between a and a cells can be defined by five stages: mate detection, cell fusion, dikaryotic filamentation, basidium formation, and spore biogenesis.

The process begins when pheromones from one haploid mating partner are sensed by the pheromone receptor of the other mating partner, setting in motion a series of events leading to cell fusion (mating). After mating, the resulting fusant begins growing as a dikaryon, a filament in which both nuclei are maintained and replicated individually. A hallmark of dikaryon formation and maintenance in basidiomycetes is the appearance and use of clamp cells to properly transport replicated nuclei across septa and into daughter filaments (Casselton and Olesnicky, 1998). C. neoformans is no different, and fused clamp cells are readily visible on the septa of mature filaments. 
In response to unknown signals, the growing dikaryotic filament terminates with the production of a fruiting body known as a basidium. Nuclear fusion and meiosis occur inside the basidium, and the four meiotic products undergo repeated mitosis before being packaged as spores and budding off the fruiting body in four long chains (Idnurm, 2010). Aerial chains can then provide a platform for spores to disperse in the environment, and models suggest that aerial spore dispersal is a mechanism for $C$. neoformans to colonize new (and possibly more hospitable) locations. $C$. neoformans spores are able to survive multiple environmental stresses that include high temperatures, desiccation, and reactive oxygen species (Botts et al., 2009).

Spores can also be phagocytosed by macrophages in the absence of opsonin, whereas yeast cells must generally be opsonized for efficient phagocytosis to occur (Giles et al., 2009). The efficiency with which $C$. neoformans is phagocytosed by macrophages is positively correlated with a decrease in human patient survival, and as such the ability of spores to be phagocytosed more readily than yeast could be a factor in spore-mediated disease (Sabiiti et al., 2014). Once spores have found a suitable environment in which to grow, they undergo germination by shedding their spore coat and resuming the process of mitotic reproduction (vegetative growth) as haploid yeast.

Only within the past two decades have the molecular events controlling development been discovered, but the previously-described morphological features of $C$. neoformans development have been known since 1975 (Kwon-Chung, 1975; Erke, 1976; Kwon-Chung and Bennett, 1978; Hull and Heitman, 2002; Idnurm et al., 2005). During that time, much has been learned regarding the nature of the pheromone/pheromone receptor system and, more recently, the transcription network regulating filamentation and later developmental events. These findings have underscored the value of not only studying the developmental pathways in $C$. neoformans as a way to better understand the evolution of transcription factor networks, but they have also revealed connections between sexual development and pathogenesis that may be applicable to other disease-causing fungi.

\section{Development begins with cell fusion and a switch to filamentous growth}

Upon encountering a mating partner, pheromone production is up-regulated in both mating types. The secreted MFa pheromone from a cells binds to its receptor on the surface of a cells (Ste3a), and conversely, the MFa pheromone binds to the Ste3a receptor on a cells (Hull and Heitman, 2002; Chung et al., 2002). After pheromone binding to these G proteincoupled receptors, a MAP Kinase cascade occurs that eventually results in the activation of the atypical pheromone response transcription factor Mat2 (X. Lin et al., 2010; Kruzel et al., 2012). Pheromone Response Factors (PRFs) in fungi integrate signals such as nitrogen limitation and the presence of a mating partner and convert them into a transcriptional response (Sugimoto et al., 1991; Hartmann et al., 1996; Zarnack et al., 2008). Once PRFs become activated, they regulate genes required for developmental events such as cell fusion. Activation of Mat2 results in its binding to the Pheromone Response Element (PRE), a 16 nucleotide cis-regulatory element found upstream of known development genes and regulators, and an increase in the expression of its target genes (X. Lin et al., 2010; Kruzel et al., 2012). The C. neoformans PRE is similar to those used by other fungi; however, Mat2 is 
highly diverged at the amino acid level, and this lack of regulator conservation in the context of binding site preservation suggests that the transcription network regulating the pheromone response has been rewired (Dolan et al., 1989; Sugimoto et al., 1991; Zarnack et al., 2008;

Sahni et al., 2009).

In addition to Mat2, two other sequence-specific High Mobility Group Domain proteins exist in C. neoformans (Hgr1 and Hgr2) and both more closely resemble PRFs from other systems than Mat2 (Kruzel, 2011; Mead, 2015; Mead et al., unpublished data). While neither protein is the PRF in $C$. neoformans, both play roles in sexual development. HGR 1 is required for wild type levels of filamentation and spore formation; that is, crosses between hgr1 1 strains exhibit fewer, shorter filaments than wild type crosses, fewer numbers of spores, and a lower frequency of spore germination (Kruzel, 2011; Mead, 2015; Mead et al., unpublished data). In addition, $H G R 1$ interacts genetically with the filament regulators STE12a and STE12a (Kruzel, 2011; Mead et al., unpublished data). HGR2 is required for wild type levels of spore production and normal frequencies of spore germination (Mead, 2015; Mead et al., unpublished data). Deletion of both HGR1 and HGR2 results in a nearly complete loss of spore production (Mead, 2015; Mead et al., unpublished data).

MAT2, HGR1, and HGR2 form an interconnected network where each gene is required for proper expression of the other two (Mead, 2015; Mead et al., unpublished data). This high level of interdependency suggests that rewiring of the ancestral network occurred, and it resulted in Mat2 assuming the role of a PRF (Kruzel et al. 2012). Because HGR1 more closely resembles PRFs from other fungal systems, it is likely that the ancestral PRF in $C$. neoformans was $H G R 1$, but at some point in the evolutionary history of $C$. neoformans, Mat2 became the functional PRF. This shift in the function of Mat 2 could occur because its targets (including $H G R 1$ and $H G R 2$ ) were likely under the control of multiple regulators which facilitated the proper expression of Mat2 target genes after they lost their Mat2dependence. This high level of connectedness is a frequently observed attribute of transcription networks and can aid in the evolution of new traits such as pathogenesis (Nobile et al., 2012; Monteiro, 2012; Sorrells and Johnson, 2015).

Two of the direct transcriptional targets of Mat2 are genes that encode the homeodomain

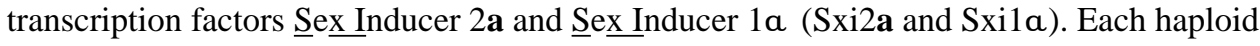
mating partner encodes only one Sxi protein: Sxi2a is found in a cells while Sxi1a is only found in a cells, and they are homologs of the cell identity factors $\mathbf{a} 1 / \mathrm{a} 2$ and bE/bW from $S$. cerevisiae and U. maydis, respectively (Johnson, 1995; Brefort et al., 2009). Following the paradigm of homeodomain protein-mediated regulation of fungal sexual development, Sxi2a and Sxila form a heterodimeric complex, and both proteins are necessary for development to occur (Hull et al., 2002; Hull et al., 2005, Kües and Casselton, 1992). Interestingly, the Sxi complex is also sufficient to drive sexual development; when either Sxi factor is expressed in cells of the opposite mating type (Sxi2a in a cells or Sxi1a in a cells), full sexual development can occur in the absence of a mating partner (Hull et al., 2002; Hull et al., 2005). This shows that the addition of only one transcription factor is sufficient to initiate and complete the series of events that lead to filamentation and sporulation. 


\section{Targets of the Sex Inducer Proteins regulate development and pathogenesis}

The Sxi proteins regulate genes directly via the Sxi Binding Site (SBS) and indirectly through an unknown mechanism that could include RNA regulation (Mead et al., 2015). The SBS is a 16 base pair sequence that is found upstream of 50 Sxi-regulated genes and consists of two half sites that correspond to each individual protein's binding site. Both proteins must be contacting DNA for the complex to exert transcriptional regulation, and the degree of regulation correlates with the conservation of that binding site relative to the cognate sequence (Mead et al., 2015).

Direct targets of the Sxi proteins include known developmental genes that harbor roles in multiple stages of the process. $C L P 1$ is a homolog of a gene required for clamp cell formation in Coprinopsis cinerea, and in C. neoformans it is a Sxi target essential for filament formation (Inada et al., 2001; Ekena et al., 2008). Another Sxi target with known developmental functions is $C P R 2$, a constitutively active $\mathrm{G}$ protein-coupled receptor that is similar to the canonical pheromone receptors STE3a and STE3a. Crosses between cpr2A strains result in clamp cells that are not fused and aberrantly long (Hsueh et al., 2009). Models suggest that $C P R 2$ competes with the canonical pheromone receptors for pheromone binding, thus lowering the overall levels of free pheromone and decreasing the odds of deviant clamp (or haploid) cell fusion.

A gene containing an argonaute domain (AGO2) was also identified as a Sxi direct target, and its null mutant was shown to have a defect in spore production (X. Wang et al., 2010). $A G O 2$ is also required for the process of Sex-Induced Silencing (SIS), an RNAi-mediated form of silencing that protects the genome from the high retrotransposon activity observed during sexual development (Janbon et al., 2010; X. Wang et al., 2013). Interestingly, SIS is absent in a sibling species of $C$. neoformans (Cryptococcus gattii) that caused an outbreak of cryptococcosis on Vancouver Island, B.C., suggesting that relatively high genomic instability could facilitate the acquisition of mutations that lead to increased virulence (D'Souza et al., 2010). Together, these data suggest that sexual development actively maintains a delicate balance between promoting mutation and controlling rampant, deleterious genome instability.

Finally, the last direct Sxi target with known developmental roles, is a gene encoding the RNA binding protein Vad1. Vad1 is responsible for proper pheromone and virulence factor regulation (Panepinto et al., 2005; Y.-D. Park et al., 2010). Vad1 regulates MFa pheromone genes directly, and vad1 $\Delta$ cells exhibit enhanced filamentation when crossed with a wild type mating partner (Y.-D. Park et al., 2010). VAD1 regulation of MFa genes acts as part of a "futile" cycle in which pheromone genes are expressed at very high levels, but the resulting RNA messages are kept at lower levels via Vad1 binding and VAD1-dependent degradation. Futile cycles are used in biology as a mechanism to quickly react to changing environments, such as a newly encountered mating partner (Y.-D. Park and Williamson, 2012). VAD1-mediated regulation, coupled with regulation of $C P R 2$, suggests that an important role of Sxi direct targets is to decrease the amount of pheromone surrounding cells that have already fused and begun sexual development. A cell cycle arrest likely occurs in $C$. 
neoformans cells once mating pheromone has been sensed (as is observed in $U$. maydis), and if spurious amounts of pheromone are constantly present even after mating has occurred, the cell cycle block would likely not allow for nascent filament elongation and continued development (Ekena et al., 2008; Heimel, Scherer, Schuler, et al., 2010).

Along with functioning during development, VAD1 is also involved in $C$. neoformans virulence and stress responses. In an insertional mutagenesis screen of $C$. neoformans, a disruption in $V A D 1$ was recovered that exhibited decreased laccase production, a canonical virulence trait (Salas et al., 1996; Panepinto et al., 2005). VAD1 is expressed in $C$. neoformans during human cryptococcosis, and cells lacking the gene are unable to cause wild type levels of disease in a mouse model of cryptococcal infection. Specifically, VAD1 aids in the evasion of and resistance to the host immune response, likely by initiating a robust and varied stress response (Qiu et al., 2013).

Targets of the Sxi proteins other than $V A D 1$ also play roles in metabolism and virulence. These include the known virulence factors $L A C 1$ and $M P K 1$ and genes for catabolic processes such as the TCA cycle, protein degradation, and $\beta$-oxidation (Kraus et al., 2003). It does not appear that the Sxi proteins play roles in virulence in vivo; however, their direct regulation of virulence factors and metabolic "stress response" genes (i.e. those involved in catabolism) suggests that $C$. neoformans has co-opted response factors that may have originally evolved to facilitate survival under sub-optimal environmental conditions during sexual development for survival in the metabolically stressful human host (Hull et al., 2004; Kronstad et al., 2012; Mead et al., 2015).

\section{ZNF2 is a regulator of development with diverse targets}

In addition to the Sxi complex, other transcription factors are required for filamentation in $C$. neoformans, and some are also connected to pathogenesis. The gene ZNF2 encodes a zinc finger domain-containing transcriptional regulator that is required for both same-sex and opposite-sex development (X. Lin et al., 2010). It is a homolog of $R B F 1$ from Ustilago maydis, a regulator of sexual development controlled directly by bE and bW (homologs of Sxi2a and Sxila) (Heimel, Scherer, Vranes, et al., 2010). In C. neoformans, however, ZNF2 is not a regulated target of the Sxi proteins and does not harbor an SBS in its promoter. Instead, $Z N F 2$ is an indirect target of MAT2 and appears to act both downstream and in parallel to it (Kruzel et al., 2012; Mead et al., 2015). When ZNF2 is overexpressed in $C$. neoformans, filamentation occurs constitutively, and the filaments are avirulent in a mouse model, again illustrating a connection between morphology and disease (L. Wang et al., 2012).

Targets of $Z N F 2$ produce many putative secreted factors and the first characterized basidiomycete adhesion, Cf11. CFL1 is regulated by $Z N F 2$, and its product is required for both adhesion and development (L. Wang et al., 2012). Specifically, CFL1 regulates the initiation of filamentation but is dispensable for filament extension and basidium formation. In addition, Cfl1 is excreted and acts as a signaling molecule to nearby cells - inducing filamentation in crosses grown on what is normally a development-repressing medium (L. Wang et al., 2013). This is surprising given that signaling molecules in eukaryotes are 
generally very small (e.g. unprocessed $M F a 1$ has a mass of approximately $4 \mathrm{kDa}$ ) and Cfl1 is a protein with a mass of over $20 \mathrm{kDa}$. While $C F L 1$ possesses interesting roles in both development and cell-cell signaling, it appears dispensable for virulence as cells overexpressing CFL1 are less virulent in mice (L. Wang et al., 2012).

Another $Z N F 2$ target that contributes to filament formation is the Pumilio domaincontaining protein Pum1 (L. Wang et al., 2014). Pumilio proteins are posttranscriptional regulators that bind to specific sequences in the $3^{\prime}$ UTRs of their target mRNAs, and they control diverse processes in a wide variety of eukaryotes (Quenault et al., 2011). In $C$. neoformans sexual development, PUM1 is important for post fusion events and regulates those processes through a diverse set of target genes like the filament-specific factor FAS1 and the meiosis-related $D M C 1$. Similar to what was observed for $Z N F 2$ (and its target CFL1); overexpression of PUM1 results in an attenuation of virulence.

While $M A T 2$ is a key regulator of development (along with its downstream targets $Z N F 2$ and $S X I 2 a / S X I 1 a$ ), a parallel pathway that does not depend on $M A T 2$ has been discovered that contains the zinc finger transcription factor $Z N F 3$. ZNF3 is required for same-sex development, and when filamentation occurs in $Z n f 3 \Delta$ strains it is severely delayed (Feretzaki and Heitman, 2013). In addition, targets of ZNF3 include genes involved in the pheromone response, sex-induced silencing, and meiosis, therefore implicating this factor as a key connection between early development events and terminal processes, including spore production.

\section{Sexual development concludes with spore formation, and the vegetative lifestyle resumes after spore germination}

Following filamentation, a fruiting body is formed (the basidium) in which the two nuclei that were previously maintained in the filament finally undergo karyogamy. The resulting diploid nucleus proceeds through meiosis, the meiotic products undergo multiple rounds of mitosis, and the mitotic products are packaged into spores. The resulting spores bud to the surface of the basidium, producing four long spore chains that extend away from the basidium. Once dispersed spores encounter a hospitable environment, they undergo germination and resume vegetative growth as yeast, completing the life cycle of $C$. neoformans. Less is known regarding the molecular mechanisms controlling these later developmental processes relative to the network that regulates mate recognition and filamentation, but recent advances have revealed glimpses into how $C$. neoformans controls meiosis, spore formation, and germination.

Two of the targets of $Z N F 3$ have been shown to be required for wild type levels of sporulation and germination, and one of those targets (SPO11) is essential for proper meiosis (Feretzaki and Heitman, 2013). SPO11 is an endonuclease that makes double strand breaks that are required for the early stages of meiosis in a variety of organisms (Keeney and Neale, 2006). In $C$. neoformans crosses between spo11 14 strains, the processes of meiosis, sporulation, and germination are severely affected (Feretzaki and Heitman, 2013). Interestingly, the germination defect can be partially alleviated by subjecting mutant spores to x-ray irradiation, supporting a role for SPO11 as a nuclease that makes breaks in DNA. 
The other target of $Z N F 3$ known to be important for spore formation and germination is $U B C 5$, a gene predicted to encode a ubiquitin-conjugating enzyme.

In addition to the requirements for proper meiosis and protein turnover, spore production is also affected by the amount of trehalose present in $C$. neoformans cells, a metabolic signal for glucose availability. Low trehalose levels (like those observed when both of the trehalases Nth1 and Nth2 are active) during development results in robust spore formation. However, when there are high amounts of trehalose present (such as during crosses of nth1 $\Delta$ th $2 \Delta$ cells), sporulation is dramatically decreased, and instead, chlamydospores (an alternative cell type) are produced (Botts et al., 2014). For this shift in development to occur, both $N T H 1$ and $N T H 2$ must be deleted from the genome, suggesting that they play overlapping roles in trehalose degradation and sexual development signaling. While NTH1 and $\mathrm{NTH} 2$ have redundant roles in controlling developmental decisions, only $\mathrm{NTH} 2$ appears to be related to virulence in a mouse model of disease, as nth $1 \Delta$ cells exhibit wild type levels of virulence both in mice and $C$. elegans models of infection, but $n$th $2 \Delta$ cells are hypervirulent (Petzold et al., 2006; Botts et al., 2014). Taken together, these results, along with the Sxi2a/Sxila data discussed above, further illustrate a connection between metabolism, development, and virulence.

Five other genes were recently identified in a proteomic study of $C$. neoformans spores as being involved in spore production to varying degrees (Huang et al., 2015). Three (DDI1, $D S T 1$, and $T O P 1$ ) were required for spore production and are known to have roles in processes as diverse as vesicle trafficking and ribosomal gene transcription in other organisms. The other two factors (EMC3 and GRE202) are required for wild type levels of spore production, and mutant crosses produce markedly fewer spores. Interestingly, another protein (Isp2) is enriched in spores, and strains lacking this gene produce more spores than a wild type cross. How these spore production-related genes and proteins are regulated by transcription networks during development is an ongoing area of research and future work will shed light on how spore production is transcriptionally controlled.

Little is known regarding the molecular mechanisms that contribute to spore formation relative to mate recognition and filamentation, but even less is understood about spore germination and the resumption of vegetative growth after sexual development. Recently, the first bone fide germination factor was discovered in C. neoformans (Isp2), but it has no conserved domains or sequence homologs in any other organisms (Huang et al., 2015). In isp $2 \Delta$ spores, the morphological changes associated with germination that occur in wild type spores appear, but the initiation of vegetative growth is delayed. Interestingly, this phenotype is not observed in spores produced from a cross containing a wild type mating partner (WT $\mathrm{x}$ isp24), indicating that Isp2 is a basidium-derived protein (akin to the "maternally deposited" products of higher eukaryotes) and raises the possibility that other products found in basidia can be packaged into nascent spores as well.

\section{Sexual development has facilitated the evolution of pathogenesis}

As we have discussed here, many regulators and effectors of development also have links to pathogenesis (Figure 1). Sexual structures such as filaments, however, are rarely found in 
patients with cryptococcosis, suggesting an indirect connection between virulence and sex. The influence sex has over pathogenesis is likely multi-faceted, and $C$. neoformans has proven to be a valuable tool for discerning how development can affect the evolution of pathogenesis.

Sex is known to be a creator of diversity in eukaryotic organisms and a producer of new phenotypes (Ni et al., 2013). In addition, sex can transfer existing traits from a small group of individuals to a population, as has been discussed previously in A. fumigatus (Camps et al., 2012). This has been observed in $C$. gattii as well where hypervirulence traits were transferred within a population via sexual reproduction, possibly facilitating an outbreak of cryptococcosis (Voelz et al., 2013). It has also been proposed that sexual development played a major role in the evolution of the outbreak strains of $C$. gattii (Fraser et al., 2005; Billmyre et al., 2014).

In addition to its active role in mutation and evolution via meiosis, sexual development can also create genetic diversity indirectly through intermediates like dikaryons and diploid cells that may act as incubators for genetic changes that are advantageous for surviving in new environments but detrimental to immediate fitness. Dikaryons of the basidiomycete Schizophyllum commune adapt better than their monokaryotic counterparts to new selection pressures, and there is evidence of genetic exchange between the two nuclei (Clark and Anderson, 2004). Clark and Anderson went on to show that this genetic exchange occurs specifically during filamentation and prior to meiosis. Future studies are needed to determine if a similar adaptation mechanism exists in C. neoformans to respond to challenging environments. If so, the mutations and variation acquired during filamentous growth in a challenging environment could be implemented for survival in a susceptible host, eventually resulting in disease.

Diploidization allows for the evolution of both transcription factor networks and new traits such as the response to specific environmental stresses and virulence more broadly. The presence of two copies of each gene allows for individual copies to drift and acquire mutations that may be beneficial. In Aspergillus nidulans, transiently produced diploid nuclei in filaments are able to confer fitness advantages that promote increases in growth, and in C. neoformans, diploidization is proposed to be one of the mechanisms by which sex facilitates mutation and diversity (Schoustra et al., 2007; Ni et al., 2013).

\section{Summary}

Fungi have proven to be extremely useful models for the study of sex and the evolution of novel attributes such as pathogenesis. The mechanisms fungi use to control development (including complex transcription factor networks) are also implemented in other organisms and exhibit dramatic plasticity to accommodate new environments. In C. neoformans it appears this plasticity has facilitated the co-option of pathways originally used to survive challenging environments for use during survival in the human lung. Future work is needed to continue building the complex network controlling development in order to fully understand the mechanisms and evolutionary history of pathogenesis in this human fungal pathogen. 


\section{Acknowledgments}

We thank Mingwei Huang, Naomi Walsh, and Sebastien Ortiz for comments on the manuscript. MEM was supported by the National Institute of Allergy and Infectious Diseases of the National Institutes of Health, under National Research Service Award T32AI055397 and an NIH R01 (AI089370) to CMH.

\section{References}

Billmyre RB, Croll D, Li W, Mieczkowski P, Carter DA, Cuomo CA, et al. Highly recombinant VGII Cryptococcus gattii population develops clonal outbreak clusters through both sexual macroevolution and asexual microevolution. mBio. 2014; 5:e01494-14. [PubMed: 25073643]

Botts MR, Giles SS, Gates MA, Kozel TR, Hull CM. Isolation and characterization of Cryptococcus neoformans spores reveal a critical role for capsule biosynthesis genes in spore biogenesis. Eukaryotic Cell. 2009; 8:595-605. [PubMed: 19181873]

Botts MR, Huang M, Borchardt RK, Hull CM. Developmental cell fate and virulence are linked to trehalose homeostasis in Cryptococcus neoformans. Eukaryotic Cell. 2014; 13:1158-1168. [PubMed: 25001408]

Brefort T, Doehlemann G, Mendoza-Mendoza A, Reissmann S, Djamei A, Kahmann R. Ustilago maydis as a pathogen. Annu Rev Phytopathol. 2009; 47:423-445. [PubMed: 19400641]

Camps SMT, Rijs AJMM, Klaassen CHW, Meis JF, O’Gorman CM, Dyer PS, et al. Molecular epidemiology of Aspergillus fumigatus isolates harboring the TR34/L98H azole resistance mechanism. Journal of Clinical Microbiology. 2012; 50:2674-2680. [PubMed: 22675126]

Casselton LA, Olesnicky NS. Molecular genetics of mating recognition in basidiomycete fungi. Microbiol Mol Biol Rev. 1998; 62:55-70. [PubMed: 9529887]

Chung S, Karos M, Chang YC, Lukszo J, Wickes BL, Kwon-Chung KJ. Molecular analysis of $C P R a$, a MATa-specific pheromone receptor gene of Cryptococcus neoformans. Eukaryotic Cell. 2002; 1:432-439. [PubMed: 12455991]

Clark TA, Anderson JB. Dikaryons of the basidiomycete fungus Schizophyllum commune: evolution in long-term culture. Genetics. 2004; 167:1663-1675. [PubMed: 15342506]

D’Souza CA, Kronstad JW, Taylor G, Warren R, Yuen M, Hu G, et al. Genome variation in Cryptococcus gattii, an emerging pathogen of immunocompetent hosts. mBio. 2010; 2:e00342-10.

Denning DW. Chronic forms of pulmonary aspergillosis. Clin Microbiol Infect. 2001; 7(Suppl 2):2531.

Dolan JW, Kirkman C, Fields S. The yeast STE12 protein binds to the DNA sequence mediating pheromone induction. Proc Natl Acad Sci USA. 1989; 86:5703-5707. [PubMed: 2668945]

Edmond MB, Wallace SE, McClish DK, Pfaller MA, Jones RN, Wenzel RP. Nosocomial bloodstream infections in United States hospitals: a three-year analysis. Clin Infect Dis. 1999; 29:239-244. [PubMed: 10476719]

Ekena JL, Stanton BC, Schiebe-Owens JA, Hull CM. Sexual development in Cryptococcus neoformans requires $C L P 1$, a target of the homeodomain transcription factors Sxila and Sxi2a. Eukaryotic Cell. 2008; 7:49-57. [PubMed: 17993575]

Erke KH. Light microscopy of basidia, basidiospores, and nuclei in spores and hyphae of Filobasidiella neoformans (Cryptococcus neoformans). J Bacteriol. 1976; 128:445-455. [PubMed: 789347]

Estella, C., Voutev, R., Mann, RS. Chapter 7 - A dynamic network of morphogens and transcription factors patterns the fly leg. In: Plaza, S., Payre, F., editors. Current Topics in Developmental Biology: Transcriptional Switches During Development. Vol. 98. Academic Press; 2012. p. 173-198.

Feretzaki M, Heitman J. Genetic circuits that govern bisexual and unisexual reproduction in Cryptococcus neoformans. PLoS Genet. 2013; 9:e1003688. [PubMed: 23966871]

Fraser JA, Diezmann S, Subaran RL, Allen A, Lengeler KB, Dietrich FS, Heitman J. Convergent evolution of chromosomal sex-determining regions in the animal and fungal kingdoms. PLoS Biol. 2004; 2:e384. [PubMed: 15538538] 
Fraser JA, Giles SS, Wenink EC, Geunes-Boyer SG, Wright JR, Diezmann S, et al. Same-sex mating and the origin of the Vancouver Island Cryptococcus gattii outbreak. Nature. 2005; 437:13601364. [PubMed: 16222245]

Giles SS, Dagenais TRT, Botts MR, Keller NP, Hull CM. Elucidating the pathogenesis of spores from the human fungal pathogen Cryptococcus neoformans. Infection and Immunity. 2009; 77:34913500. [PubMed: 19451235]

Hartmann HA, Kahmann R, Bölker M. The pheromone response factor coordinates filamentous growth and pathogenicity in Ustilago maydis. EMBO J. 1996; 15:1632-1641. [PubMed: 8612587]

Heimel K, Scherer M, Schuler D, Kämper J. The Ustilago maydis Clp1 protein orchestrates pheromone and b-dependent signaling pathways to coordinate the cell cycle and pathogenic development. Plant Cell. 2010; 22:2908-2922. [PubMed: 20729384]

Heimel K, Scherer M, Vranes M, Wahl R, Pothiratana C, Schuler D, et al. The transcription factor $\mathrm{Rbf1}$ is the master regulator for b-mating type controlled pathogenic development in Ustilago maydis. PLoS Pathog. 2010; 6:e1001035. [PubMed: 20700446]

Hsueh Y-P, Xue C, Heitman J. A constitutively active GPCR governs morphogenic transitions in Cryptococcus neoformans. EMBO J. 2009; 28:1220-1233. [PubMed: 19322200]

Huang M, Hebert AS, Coon JJ, Hull CM. Protein composition of infectious spores reveals novel sexual development and germination factors in Cryptococcus. PLoS Genet. 2015; 11:e1005490. [PubMed: 26313153]

Hull CM, Heitman J. Genetics of Cryptococcus neoformans. Annu Rev Genet. 2002; 36:557-615. [PubMed: 12429703]

Hull CM, Boily M-J, Heitman J. Sex-specific homeodomain proteins Sxi1a and Sxi2a coordinately regulate sexual development in Cryptococcus neoformans. Eukaryotic Cell. 2005; 4:526-535. [PubMed: 15755915]

Hull CM, Cox GM, Heitman J. The alpha-specific cell identity factor Sxila is not required for virulence of Cryptococcus neoformans. Infect Immun. 2004; 72:3643-3645. [PubMed: 15155676]

Hull CM, Davidson RC, Heitman J. Cell identity and sexual development in Cryptococcus neoformans are controlled by the mating-type-specific homeodomain protein Sxila. Genes \& Development. 2002; 16:3046-3060. [PubMed: 12464634]

Idnurm A. A tetrad analysis of the basidiomycete fungus Cryptococcus neoformans. Genetics. 2010; 185:153-163. [PubMed: 20157004]

Idnurm A, Bahn Y-S, Nielsen K, Lin X, Fraser JA, Heitman J. Deciphering the model pathogenic fungus Cryptococcus neoformans. Nature Reviews Microbiology. 2005; 3:753-764. [PubMed: 16132036]

Inada K, Morimoto Y, Arima T, Murata Y, Kamada T. The clp1 gene of the mushroom Coprinus cinereus is essential for A-regulated sexual development. Genetics. 2001; 157:133-140. [PubMed: 11139497]

Janbon G, Maeng S, Yang D-H, Ko Y-J, Jung K-W, Moyrand F, et al. Characterizing the role of RNA silencing components in Cryptococcus neoformans. Fungal Genet Biol. 2010; 47:1070-1080. [PubMed: 21067947]

Johnson AD. Molecular mechanisms of cell-type determination in budding yeast. Curr Opin Genet Dev. 1995; 5:552-558. [PubMed: 8664541]

Keeney S, Neale MJ. Initiation of meiotic recombination by formation of DNA double-strand breaks: mechanism and regulation. Biochem Soc Trans. 2006; 34:523-525. [PubMed: 16856850]

Kim J, Chu J, Shen X, Wang J, Orkin SH. An extended transcriptional network for pluripotency of embryonic stem cells. Cell. 2008; 132:1049-1061. [PubMed: 18358816]

Kraus PR, Fox DS, Cox GM, Heitman J. The Cryptococcus neoformans MAP kinase Mpk1 regulates cell integrity in response to antifungal drugs and loss of calcineurin function. Molecular Microbiology. 2003; 48:1377-1387. [PubMed: 12787363]

Kronstad J, Saikia S, Nielson ED, Kretschmer M, Jung W, Hu G, et al. Adaptation of Cryptococcus neoformans to mammalian hosts: integrated regulation of metabolism and virulence. Eukaryotic Cell. 2012; 11:109-118. [PubMed: 22140231] 
Kruzel, EK. Doctoral Dissertation. ProQuest Dissertations Publishing, Proquest Dissertations and Theses Database; 2011. Mapping the transcriptional regulatory mechanisms governing sexual development in the human fungal pathogen Cryptococcus neoformans. UMI No. 3489088

Kruzel EK, Giles SS, Hull CM. Analysis of Cryptococcus neoformans sexual development reveals rewiring of the pheromone-response network by a change in transcription factor identity. Genetics. 2012; 191:435-449. [PubMed: 22466042]

Kües U, Casselton LA. Homeodomains and regulation of sexual development in basidiomycetes. Trends Genet. 1992; 8:154-155. [PubMed: 1369739]

Kvaal C, Lachke SA, Srikantha T, Daniels K, McCoy J, Soll DR. Misexpression of the opaque-phasespecific gene PEP1 (SAP1) in the white phase of Candida albicans confers increased virulence in a mouse model of cutaneous infection. Infection and Immunity. 1999; 67:6652-6662. [PubMed: 10569787]

Kwon-Chung KJ. A new genus, Filobasidiella, the perfect state of Cryptococcus neoformans. Mycologia. 1975; 67:1197-1200. [PubMed: 765816]

Kwon-Chung KJ, Bennett JE. Distribution of a and a mating types of Cryptococcus neoformans among natural and clinical isolates. Am J Epidemiol. 1978; 108:337-340. [PubMed: 364979]

Lengeler KB, Fox DS, Fraser JA, Allen A, Forrester K, Dietrich FS, Heitman J. Mating-type locus of Cryptococcus neoformans: a step in the evolution of sex chromosomes. Eukaryotic Cell. 2002; 1:704-718. [PubMed: 12455690]

Lengeler KB, Wang P, Cox GM, Perfect JR, Heitman J. Identification of the MATa mating-type locus of Cryptococcus neoformans reveals a serotype A MATa strain thought to have been extinct. Proc Natl Acad Sci USA. 2000; 97:14455-14460. [PubMed: 11121047]

Lin SJ, Schranz J, Teutsch SM. Aspergillosis case-fatality rate: systematic review of the literature. Clin Infect Dis. 2001; 32:358-366. [PubMed: 11170942]

Lin X, Jackson JC, Feretzaki M, Xue C, Heitman J. Transcription factors Mat2 and Znf2 operate cellular circuits orchestrating opposite- and same-sex mating in Cryptococcus neoformans. PLoS Genet. 2010; 6:e1000953. [PubMed: 20485569]

Lin X, Hull CM, Heitman J. Sexual reproduction between partners of the same mating type in Cryptococcus neoformans. Nature. 2005; 434:1017-1021. [PubMed: 15846346]

Litvintseva AP, Marra RE, Nielsen K, Heitman J, Vilgalys R, Mitchell TG. Evidence of sexual recombination among Cryptococcus neoformans serotype A isolates in Sub-Saharan Africa. Eukaryotic Cell. 2003; 2:1162-1168. [PubMed: 14665451]

MacArthur S, Li X-Y, Li J, Brown JB, Chu HC, Zeng L, et al. Developmental roles of 21 Drosophila transcription factors are determined by quantitative differences in binding to an overlapping set of thousands of genomic regions. Genome Biol. 2009; 10:R80. [PubMed: 19627575]

Mead, ME. Doctoral Dissertation. ProQuest Dissertations Publishing, Proquest Dissertations and Theses Database; 2015. Unraveling the transcriptional network regulating sexual development in the human fungal pathogen Cryptococcus neoformans.. UMI No. 3723113

Mead ME, Stanton BC, Kruzel EK, Hull CM. Targets of the Sex Inducer homeodomain proteins are required for fungal development and virulence in Cryptococcus neoformans. Molecular Microbiology. 2015; 95:804-818. [PubMed: 25476490]

Mead ME, Kruzel EK, Hull CM. Genetic characterization of High-Mobility Group transcription regulators during the sexual development of Cryptococcus neoformans reveals an integrated control network. Unpublished Data.

Miller MG, Johnson AD. White-opaque switching in Candida albicans is controlled by mating-type locus homeodomain proteins and allows efficient mating. Cell. 2002; 110:293-302. [PubMed: 12176317]

Monteiro A. Gene regulatory networks reused to build novel traits. Bioessays. 2012; 34:181-186. [PubMed: 22223407]

Ni M, Feretzaki M, Li W, Floyd-Averette A, Mieczkowski P, Dietrich FS, Heitman J. Unisexual and heterosexual meiotic reproduction generate aneuploidy and phenotypic diversity de novo in the yeast Cryptococcus neoformans. PLoS Biol. 2013; 11:e1001653. [PubMed: 24058295] 
Nobile CJ, Fox EP, Nett JE, Sorrells TR, Mitrovich QM, Hernday AD, et al. A Recently evolved transcriptional network controls biofilm development in Candida albicans. Cell. 2012; 148:126138. [PubMed: 22265407]

O'Gorman CM, Fuller HT, Dyer PS. Discovery of a sexual cycle in the opportunistic fungal pathogen Aspergillus fumigatus. Nature. 2009; 457:1-5.

Panepinto J, Liu L, Ramos J, Zhu X, Valyi-Nagy T, Eksi S, et al. The DEAD-box RNA helicase Vad1 regulates multiple virulence-associated genes in Cryptococcus neoformans. J Clin Invest. 2005; 115:632-641. [PubMed: 15765146]

Paoletti M, Rydholm C, Schwier EU, Anderson MJ, Szakacs G, Lutzoni F, et al. Evidence for sexuality in the opportunistic fungal pathogen Aspergillus fumigatus. Current Biology. 2005; 15:1242-1248. [PubMed: 16005299]

Park BJ, Wannemuehler KA, Marston BJ, Govender N, Pappas PG, Chiller TM. Estimation of the current global burden of cryptococcal meningitis among persons living with HIV/AIDS. AIDS. 2009; 23:525-530. [PubMed: 19182676]

Park Y-D, Williamson PR. "Popping the clutch": novel mechanisms regulating sexual development in Cryptococcus neoformans. Mycopathologia. 2012; 173:359-366. [PubMed: 21912854]

Park Y-D, Panepinto J, Shin S, Larsen P, Giles S, Williamson PR. Mating pheromone in Cryptococcus neoformans is regulated by a transcriptional/degradative "futile" cycle. Journal of Biological Chemistry. 2010; 285:34746-34756. [PubMed: 20801870]

Petzold EW, Himmelreich U, Mylonakis E, Rude T, Toffaletti D, Cox GM, et al. Characterization and regulation of the trehalose synthesis pathway and its importance in the pathogenicity of Cryptococcus neoformans. Infection and Immunity. 2006; 74:5877-5887. [PubMed: 16988267]

Pittet MJ, Nahrendorf M, Swirski FK. The journey from stem cell to macrophage. Ann NY Acad Sci. 2014; 1319:1-18. [PubMed: 24673186]

Qiu J, Olszewski MA, Williamson PR. Cryptococcus neoformans growth and protection from innate immunity are dependent on expression of a virulence-associated DEAD-box protein, Vad1. Infection and Immunity. 2013; 81:777-788. [PubMed: 23264050]

Quenault T, Lithgow T, Traven A. PUF proteins: repression, activation, and mRNA localization. Trends in Cell Biology. 2011; 21:104-112. [PubMed: 21115348]

Sabiiti W, Robertson E, Beale MA, Johnston SA, Brouwer AE, Loyse A, et al. Efficient phagocytosis and laccase activity affect the outcome of HIV-associated cryptococcosis. J Clin Invest. 2014; 124:2000-2008. [PubMed: 24743149]

Sahni N, Yi S, Daniels KJ, Srikantha T, Pujol C, Soll DR. Genes selectively up-regulated by pheromone in white cells are involved in biofilm formation in Candida albicans. PLoS Pathog. 2009; 5:e1000601. [PubMed: 19798425]

Salas SD, Bennett JE, Kwon-Chung KJ, Perfect JR, Williamson PR. Effect of the laccase gene CNLAC1, on virulence of Cryptococcus neoformans. J Exp Med. 1996; 184:377-386. [PubMed: 8760791]

Sasse C, Hasenberg M, Weyler M, Gunzer M, Morschhauser J. White-opaque switching of Candida albicans allows immune evasion in an environment-dependent fashion. Eukaryotic Cell. 2013; 12:50-58. [PubMed: 23125350]

Schoustra SE, Debets AJM, Slakhorst M, Hoekstra RF. Mitotic recombination accelerates adaptation in the fungus Aspergillus nidulans. PLoS Genet. 2007; 3:e68. [PubMed: 17465683]

Sorrells TR, Johnson AD. Making sense of transcription networks. Cell. 2015; 161:714-723. [PubMed: 25957680]

Sugimoto A, Iino Y, Maeda T, Watanabe Y, Yamamoto M. Schizosaccharomyces pombe ste11+ encodes a transcription factor with an HMG motif that is a critical regulator of sexual development. Genes \& Development. 1991; 5:1990-1999. [PubMed: 1657709]

Voelz K, Ma H, Phadke S, Byrnes EJ, Zhu P, Mueller O, et al. Transmission of hypervirulence traits via sexual reproduction within and between lineages of the human fungal pathogen Cryptococcus gattii. PLoS Genet. 2013; 9:e1003771. [PubMed: 24039607]

Wang L, Tian X, Gyawali R, Lin X. Fungal adhesion protein guides community behaviors and autoinduction in a paracrine manner. Proc Natl Acad Sci USA. 2013; 110:11571-11576. [PubMed: 23798436] 
Wang L, Tian X, Gyawali R, Upadhyay S, Foyle D, Wang G, et al. Morphotype transition and sexual reproduction are genetically associated in a ubiquitous environmental pathogen. PLoS Pathog. 2014; 10:e1004185. [PubMed: 24901238]

Wang L, Zhai B, Lin X. The link between morphotype transition and virulence in Cryptococcus neoformans. PLoS Pathog. 2012; 8:e1002765. [PubMed: 22737071]

Wang X, Darwiche S, Heitman J. Sex-induced silencing operates during opposite-sex and unisexual reproduction in Cryptococcus neoformans. Genetics. 2013; 193:1163-1174. [PubMed: 23378067]

Wang X, Hsueh Y-P, Li W, Floyd A, Skalsky R, Heitman J. Sex-induced silencing defends the genome of Cryptococcus neoformans via RNAi. Genes \& Development. 2010; 24:2566-2582. [PubMed: 21078820]

Zarnack K, Eichhorn H, Kahmann R, Feldbrgge M. Pheromone-regulated target genes respond differentially to MAPK phosphorylation of transcription factor Prf1. Molecular Microbiology. 2008; 69:1041-1053. [PubMed: 18627457] 


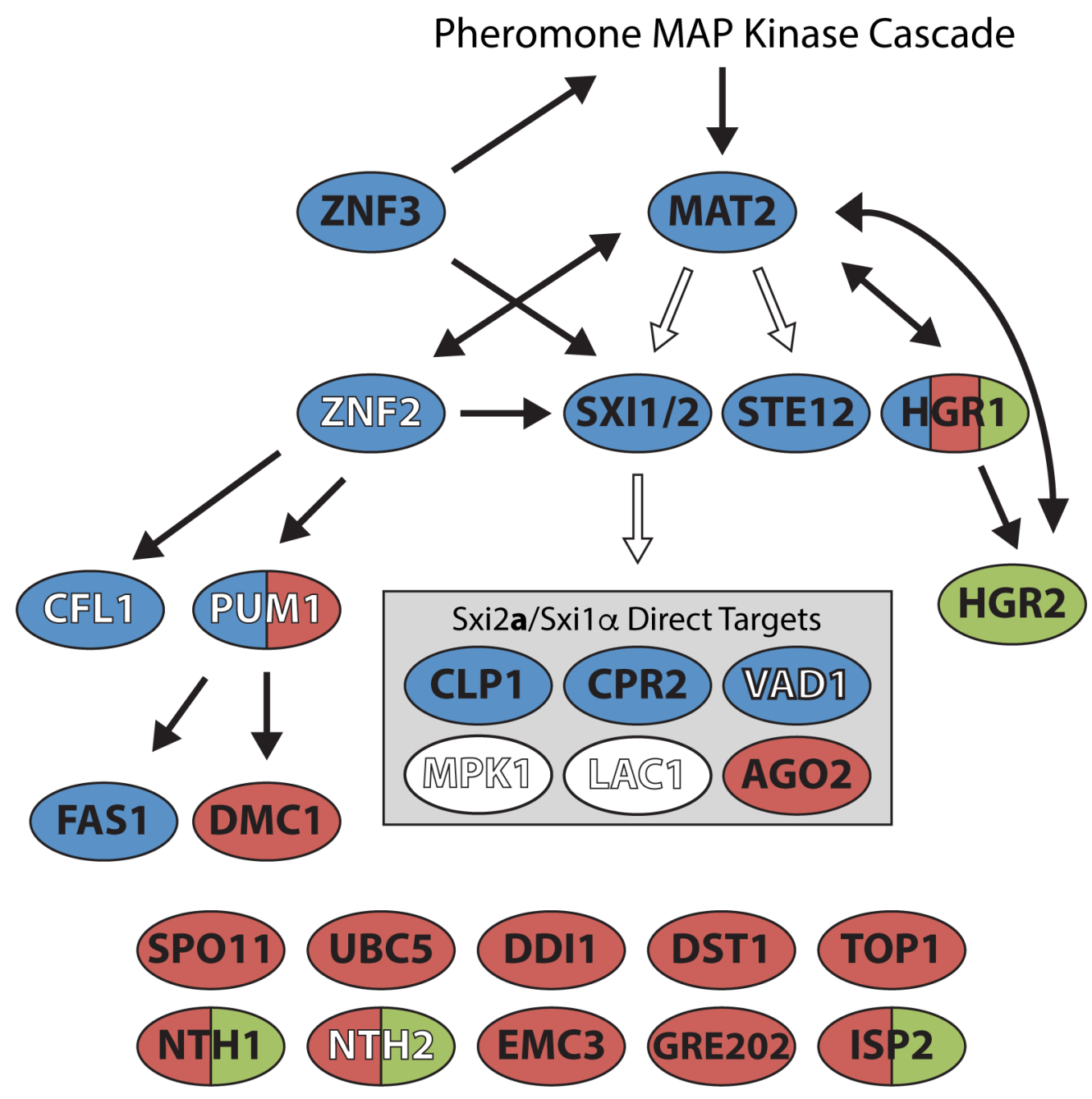

Figure 1. A complex transcriptional control network regulates sexual development in $C$. neoformans

Genes involved in sexual development are represented with different-colored ovals. Colors are based on the stage at which null mutants exhibit phenotypes in development: blue filamentation, red - spore production, green - spore germination, white - no known sexual development phenotype. Genes labeled with a white font are involved in virulence. White arrows - direct regulation via interactions between transcription factors and identified binding sites in the promoters of their targets. Black arrows - genetic interactions that may or may not occur via direct binding to target genes. Direct Sxi2a/Sxi1a targets of interest are boxed in gray. 